\title{
New thinking on health and fitness
}

Received (in revised form): 28 November 2003

\begin{abstract}
Jim Fallon
worked in industry for eight years, then spent 11 years with HSBC. This included five years in the Specialised Financing division of Samuel Montagu where he had responsibility for originating and executing leveraged debt and capital markets business. In 1998 he became a founding member of HSBC's Consumer and Leisure team with specific responsibility for $M \& A$ advice and financing within the pubs, brewing and leisure sectors. Jim was one of the four founding partners of McQueen Limited when it was established in June 2002. McQueen is an independent corporate finance advisory firm which specialises in the consumer, leisure and retail sectors. It provides advice on strategy, mergers and acquisitions, raising debt and equity finance, and executes transactions with both corporate and private equity clients.
\end{abstract}

\section{Abstract}

The health and fitness industry has seen rapid growth and ownership change over recent years. This has changed the shape of the industry and the competitive dynamics considerably. This paper considers some of the implications for the future of the industry in the context of these recent changes and discusses the likely direction of the health and fitness industry over the next few years.

\section{Keywords:}

health, fitness, lifecycle, industry

\section{INDUSTRY LIFE CYCLE}

Most industries or products have a life cycle. ${ }^{1}$ Products typically follow a cycle of introduction, growth, maturity, decline and finally termination. A good example of this is the video recorder. This product has passed through the introduction and growth stages and is now in maturity (or even decline based on the speed of growth in DVDs). It is likely to move into decline in the coming years as new technology surpasses the product, and the video recorder will eventually reach a termination point.

This analogy of a life cycle can be utilised to look at particular industries. New or reinvigorated industries follow an industry lifecycle curve (Figure 1). The new industry can start slowly, build up growth momentum and then reach a mature phase of stable, nogrowth performance. Often the next phase is decline unless a new energy level is introduced through further innovation or technology. When a product or industry emerges it is the innovative consumers that initially take it up. In the case of health and fitness, the innovators tend to be the people very keen on fitness generally. 


\section{Typical product life cycle}

Sustainable growth

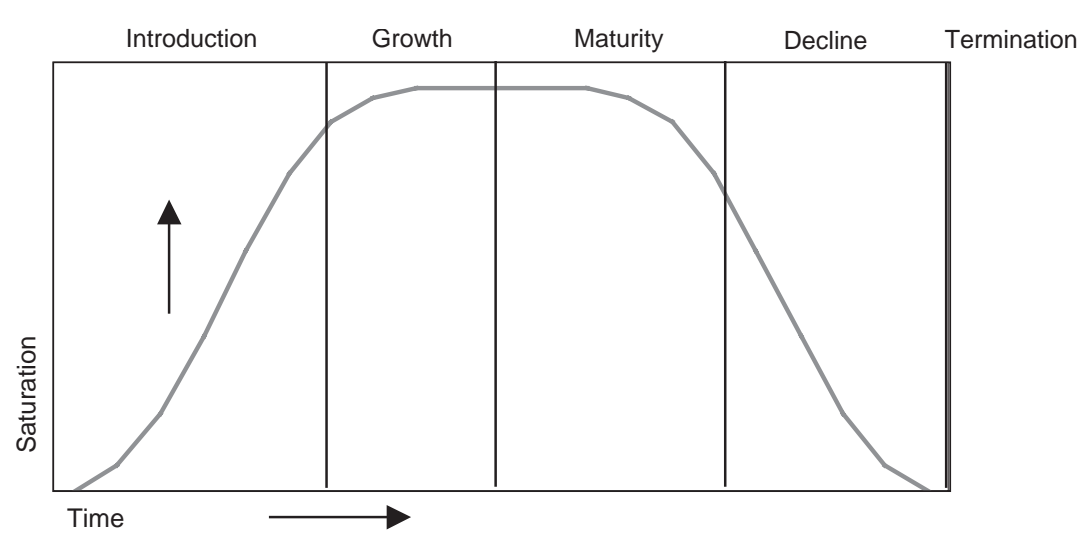

Figure 1: The product life cycle

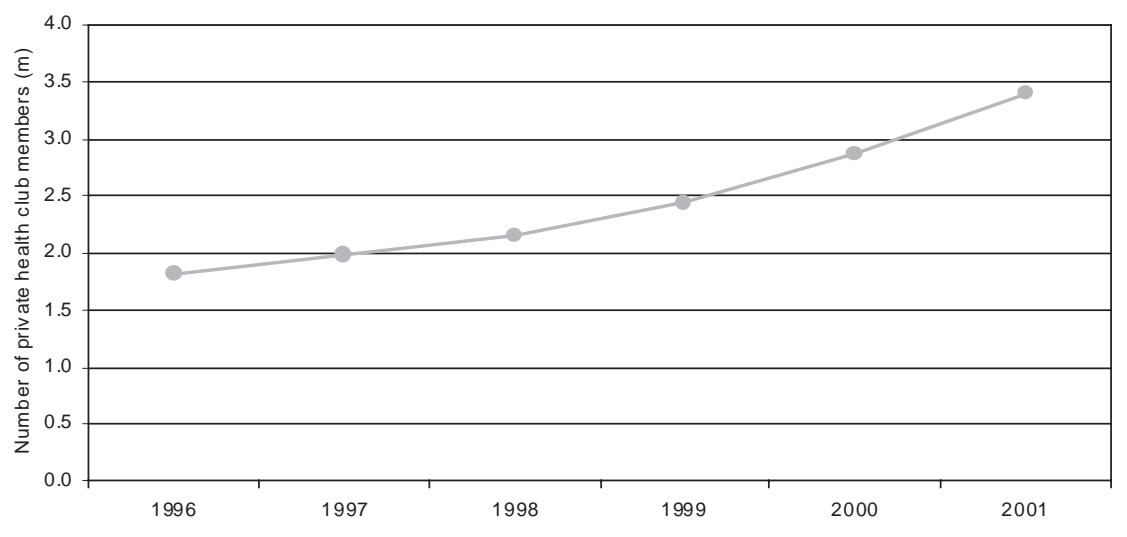

Figure 2: Growth in the number of private health club members

As the market develops, more consumers adopt the product. All of a sudden, people are talking about it and word of mouth combined with promotional and marketing efforts deliver a significant growth profile for the industry. This was certainly the case for the health and fitness industry (Figure 2). ${ }^{2}$

This growth has a defined life, as the rate of growth cannot mathematically continue indefinitely. As the pace of growth begins to slow (early maturity) the industry moves into a phase of consolidation. As the high earnings growth driven by increasing numbers of units and members reduces, consolidation of the market is required to maintain the earnings growth model for investors.

Finally one sees late maturity. At this stage, the consolidation has taken place and there are a few players dominating the entire market. Market growth is now very low, with profit growth driven through efficient and innovative management rather than market growth. As one can see from Figure 3, the health and fitness industry does not appear to have a significant decline and termination element to it, as the current view is that the industry is here to stay. This is due to a growing awareness of the importance 


\section{Changing societies have resulted in an increased focus on health and fitness}

\section{Entrepreneurs fund the innovation phase}

of health and fitness in modern society, combined with new technology leading to less physical work roles for Western society as a whole, resulting in the need for a more structured exercise regime within people's daily lives. As working life becomes more time consuming and increasingly difficult to predict, people are opting for exercise which can be flexible and therefore fit around a constantly changing lifestyle. Membership of a health and fitness club can be structured to suit this lifestyle. A further push towards more interest in health and fitness is the growing awareness of nutritional issues and growing obesity within the population. The phenomenal success of the Atkins diet publication ${ }^{3}$ clearly demonstrates the interest, if not necessarily the discipline, in maintaining a balanced physique.

As the industry is progressing through the various stages of development (Figure 3), different opportunities arise and different funding partners wish to take advantage of these opportunities.

In the innovation period it is personal entrepreneurial money and business angels' finance that stimulates this phase. Typically, individuals within the industry see opportunities but need to prove the ideas and thoughts before the professional investors enter the market. As the concepts are proven, private equity funders become interested. They are looking for strong teams with good ideas that require development capital to fund the next phase of growth and/ or concept roll-out (ie reducing the risk profile). They tend to provide funding with a view to a three- to five-year repayment and exit profile.

When the businesses within the industry reach a certain critical mass and further funding is required for clearly identified roll-out opportunities, institutional investors become interested and often place high valuation levels on these companies. The high values are driven by the view that holding stocks in these businesses will allow the fund managers to outperform the general market significantly.

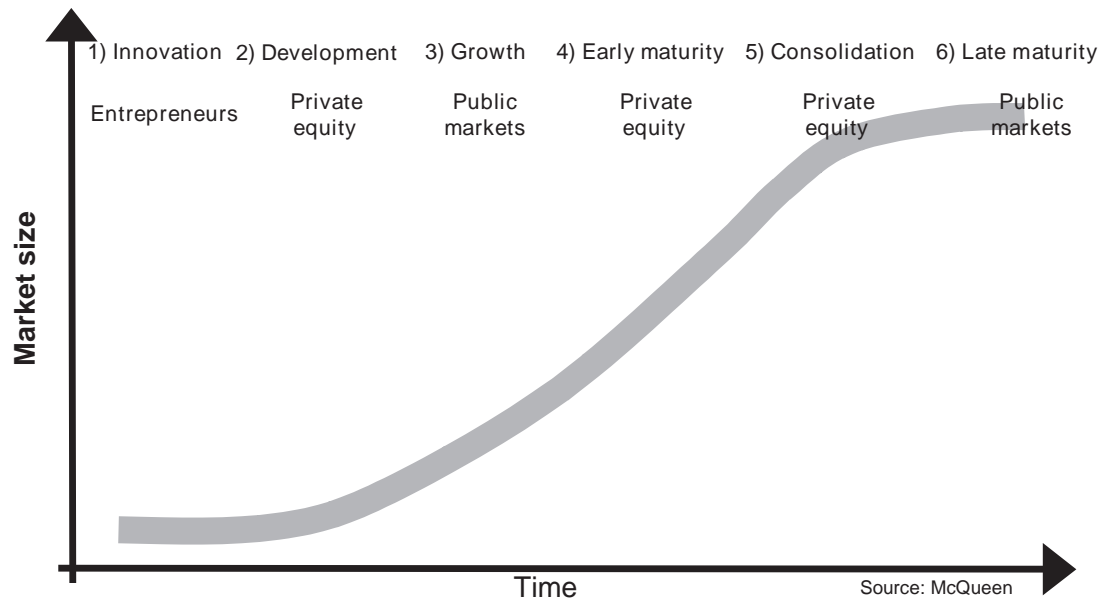

Figure 3: The health and fitness market 


\section{Growth expectation} driven valuations?

\section{Cashflow valuations exceed stock market valuations}

\section{Private companies consolidate before coming back to the public markets}

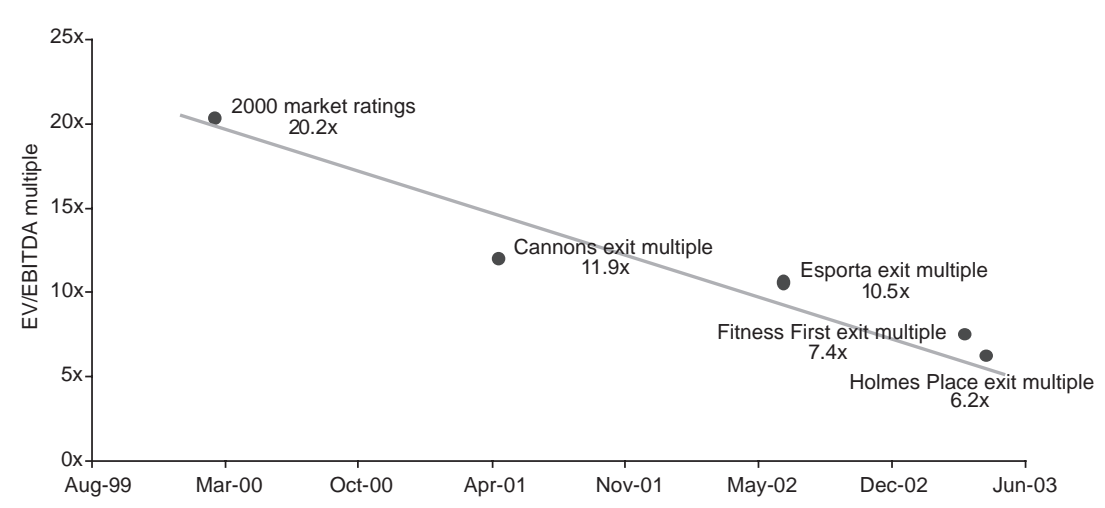

Figure 4: Valuation multiples over time

At this point the original private equity investors sell the holdings, take a good profit and leave the next phase of development to be funded by the institutional investor market. The industry clearly saw this phase around five years ago, with a number of businesses going through stock market flotations and receiving very high valuation multiples in the early years thereafter.

As the market development growth slows, the stock market begins to value the business at a lower level. As it becomes clear that the rate of growth in the business must slow due to scale and some new sites are seen to deliver lower returns, valuations can reduce quite dramatically. This is not necessarily due to poor performance by the business (although reality has demonstrated mixed performance from the existing players). It is at this point of the industry's early maturity that private equity investors see value through continued market growth, albeit at a slower rate, and future consolidation of the industry. Therefore, an arbitrage opportunity arises and private transactions occur (when publicly quoted companies are acquired by private companies and the stock market listing is cancelled). Figure $4^{4}$ demonstrates the clear trend of reducing valuation multiples over time as the industry growth began slowing, supply overtook demand and performance suffered as a result.

The next phase in the industry life cycle is consolidation. This will be driven by different private equity perspectives on the industry and fixed exit requirements. Some private equity owners will take the opportunity to sell, while others will buy and take advantage of the synergies in head office and other economies of scale.

The final late-maturity phase is often accommodated by the stock market, as the players will be substantial in size and could produce very strong dividend yields at this point (although limited but predictable growth). The stock market often gives a premium value to market-leading businesses as they tend to be able to defend this market position and therefore survive and prosper in the medium to longer term. Typically these investments will 


\section{Rapid roll out leads to marginal returns ...}

\section{... therefore now unit growth will slow further}

\section{Overseas expansion has proved problematic for most}

... market consolidation ...

\section{... and operational improvements}

provide strong income but limited capital growth in the medium to longer term.

\section{HOW WILL THE THEORY AFFECT THE INDUSTRY OVER THE NEXT FEW YEARS?}

The industry is already experiencing a significant reduction in the number of new club openings. The number of new clubs opened per year was running at an unsustainably high rate a few years ago. This led to significant competition for sites and marginal-return units beginning to find their way into portfolios. New unit openings have seen a steep reduction in number since 2000. This level is likely to reduce rather than increase under private equity ownership. Unit growth in the future is more likely to be driven through acquiring distressed assets and smaller businesses rather than opening brand-new sites. The industry could also see the sale of some of the more marginal units for alternative use.

There is also much less likely to be aggressive overseas expansion, as this has tended to produce poor returns for many of the UK operators. The private equity owners will be focusing on improving the returns in the core business markets before expanding significantly in new territories. International expansion can be difficult to achieve successfully due to a number of reasons, including issues relating to different markets and cultures, management team stretch and inexperience in international expansion.

\section{NEW OWNERS, NEW THINKING}

The private equity ownership discipline is quite simple. They will look at cash flow very closely in order to service relatively high debt levels. They will also unemotionally consider cost reductions across the business. Interestingly, the majority of the return to the private equity shareholders is achieved through a sale of the business rather than current pay dividends.

Consolidation will be the next industry phase. Private equity owners will seek operational improvements and synergies to be gained from consolidation in order to create the returns they need to see for their investors. The most overcrowded market position is in health and fitness club premium offerings, which will see the most mergers and acquisition activity over the next few years. It will be interesting to see how many hotels maintain ownership and operation of their health and fitness businesses. There is a strong likelihood that focused operators will be in a position to provide the services required by hotels at a significantly reduced cost in the short to medium term.

During and after the consolidation phase the new areas of focus will not be roll-out but more organic growth through improved operational standards, increasing the average spend per member, improved database utilisation and exporting best practices across the group. 
Best of breed will emerge

\section{The customer is a complex creature}

\section{Lifestyle may well be the key driver}

As the market growth rate reduces other methods of improving returns become more relevant. Increasing the leverage (ie the amount of debt in the business) increases the returns to equity shareholders but can significantly increase the risk profile of the business, thus operational improvements will become a key driver.

A more sustainable method of improving returns is a combination of reducing costs, reducing the member attrition rates, increasing the spend per member and making the product more accessible to a wider audience. To do any and all of this requires a different way of thinking about the product offering and the target audience.

As the market sophistication develops, the businesses which do not embrace a more professional and commercial approach will find difficulty in maintaining good returns when compared to their peer group.

\section{IS THE HEALTH AND FITNESS INDUSTRY OFFERING A PRODUCT, EVENT OR LIFESTYLE?}

To maximise the yield on the health and fitness asset a business might own, it is critically important to understand what it is that is being sold and to whom.

Why do people visit a health and fitness club?

- They may like swimming, going to the gym or specific classes, in which case they will attend wherever the product is good quality and suits their individual needs.

- They may like to get out of the house for a few hours and meet up with a few friends for social interaction, gossip and fitness activities. This is a different proposition than purely wanting to attend a class for exercise purposes. An environment needs to be available to allow that interaction and facilitate easy organisation of the event. For example, the coffee in the food and beverage area afterwards is as much a part of the offering as the class or gym equipment itself.

- A further type of member may prefer the lifestyle element of being a club member. For example, they meet like-minded people, possibly with a similar background or job type. They join a club because it is helpful to their self-esteem or business to say they are a member of this particular club. Again, this is a different proposition to the product or event purchase discussed above.

Understanding the customer or member and what it is they require from using the facility is key to maximising the value which can be created from the facility and the returns which can be generated from the assets. Marketing in this environment is significantly more complex than offering a health and fitness product to a market that is desperate for the product when it is in limited supply. It is important to understand the behaviour of the consumer and the 


\section{Marketing will be a key driver of growth}

\section{Market will continue to grow ...}

\section{... there will be a reduction in brands ....}

\section{... and better value for the consumer}

types of marketing message that are effective to them. For example, it is essential to use marketing messages around the correct reference groups, as the product usage is highly visible and therefore being seen to support one product or another will affect the way social groups see the individual (either actually or in the perception of the individual). ${ }^{5}$

Marketing and product innovation will become increasingly important to maintain business growth and increasing returns as industry growth becomes more difficult to achieve.

\section{SUMMARY}

The health and fitness industry is in the early maturity phase of the industry life cycle. This will lead to significant consolidation over the next few years. The industry has already seen a number of the smaller operators facing difficulties.

The industry is also seeing a much reduced pace of new unit rollout. The likelihood is that the acquisition of existing sites will be the key growth driver moving forward. Notwithstanding the current oversupply, the market will continue to grow in the medium term due to an increasing awareness of health issues coupled with advantageous demographic trends and increasing disposable income levels. Industry best practices will emerge as each business begins to focus much more aggressively on how to maximise its contribution with limited growth.

From a consumer perspective, there will be a more competitive environment which will lead to a reduction in the number of brands, with clear winners and losers. With the application of professional management techniques across the industry, it should see a more dynamic business model emerging which should create value to its shareholders and innovation and better value to the consumer.

\section{References}

1. Smallwood, J. E. (1988) 'The product life cycle: A key to strategic marketing', in Enis, B. M. and Cox, K. K. (eds) Marketing Classics, Sixth Edition, Allyn and Bacon Inc., Needham Heights, MA.

2. Mintel (2003) 'The Brits get fit', press release available at http://reports.mintel.com sinatra/mintel/press_release/,May.

3. Atkins, R. C. (2003) Atkins for life: The Complete Controlled Carb Program for Permanent Weight Loss and Good Health, St Martin's Press, NY.

4. Valuation multiples over time, Source: HSBC Research March 2000, Offer documents.

5. Engel, J. F., Blackwell, R. D. and Miniard, P. W. (1990) Consumer Behaviour, The Dryden Press, International Edition. 